\title{
Outnumbered and surrounded: Women working in male-dominated research fields
}

\section{Malin Kylander on the obstacles still faced by women in science and how we can tackle them}

At one of the entrances to my department at Stockholm University, you will find a wall of portraits. These portraits are of the professors who have worked at our department since its beginnings in 1881. Among the portraits, you will find geology giants like Gerard De Geer and Lennart von Post, but you will not find a single woman. The reason for this is of course partly historical, and partly the rugged nature of the geology discipline. So, what challenges do women in male-dominated research areas face and what can we all do to increase the presence of women and other minorities in these fields?

\section{Historical hurdles}

During the early waves of feminism in the $19^{\text {th }}$ century, women had to fight to get into both classrooms and voting booths. Sweden for example, only saw its first officially registered female university student, Betty Petterson, start in 1871 at Uppsala University. Women were barred from reading a number of programmes and were certainly not allowed to study for a higher degree. Even the first female

Department of Mathematics at Stockholm University in 1884, had not been allowed to attend classes in her native Russia. Needing the permission of her father or husband to leave the country, she had a fictitious marriage and left for Germany where she attended classes by special permission or received private lessons. She finally completed her PhD summa cum laude at the University of Göttingen in 1874.

Women of the time were expected to be modest and ladylike, conditions that contrast with digging around in rocks and dirt. Mary Anning, the famous English palaeontologist, made a number of important fossil finds, but was often not credited for her work. Indeed, she was barred from the Geological Society of London because she was a woman. We can only imagine what a curious figure she would have been for her contemporaries, with her geology hammer and cumbersome skirts combing the seashore. If she had lived until 1888, she might have breathed a sigh of relief when the Rational Dress Society of London recommended that "the maximum weight of underclothing [for women] should not exceed seven pounds"1. It would appear that education, social constructs, and even clothing, slowed the rise of women in geology.

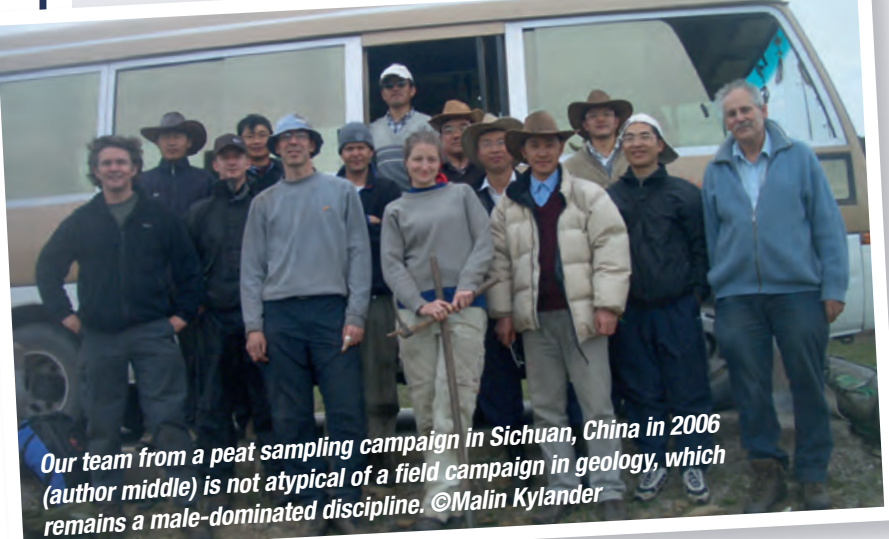

\section{Women in the} sciences today

Geology remains a male-dominated discipline where challenging field conditions and hammers are more associated with the "lads" than the "ladies". The proportion of women completing PhDs in the geosciences has

professor in northern Europe, Sofia Kovalevskaya, who started at the risen from $4 \%$ in 1974 to $40 \%$ by 2009 . However, women hold just $13 \%$ of full professorial positions (US numbers for
2010-2011)2. The dearth of female professors in geology, and elsewhere in the natural sciences, could lead female students and junior researchers to wonder if there is a place for them in academics.

Hypotheses as to why women still haven't reached these top positions are many and can be linked to the individuals, the institutions in which they work, and the cultural baggage we all carry. In the geosciences many women leave academia between postdoc and assistant professor positions. Some women (and men) chose to leave academia due to their belief that they lack the traits required for research, for example, ambition, leadership and the ability to handle criticism. These losses could be minimized in a more supportive and encouraging environment. Others are faced with lifestyle choices, such as family or immobility due to a partner's job. In some countries, like Sweden, women are well supported by the social welfare system if they chose to have a family. Women working in countries without this type of culture may look to their institutions for such support and find it lacking. Institutions may not distribute resources (laboratory space, money) and tasks fairly, with "soft issues" like mentorship and administration belonging in the female realm.

\section{What does the research suggest?}

It is suggested that gender imbalances in the sciences will even out with time. A recent study looking at differences in productivity between men and women, a key parameter in promotion, shows however, that the much-lauded academic pipeline is still leaking. The study's authors, Peter van den Besselaar and Ulf Sandström, base their study on a database of 47,000 Swedish researchers covering 2008-2011³. Researchers were divided into seven different productivity 
classes for different disciplines. They found that within the same productivity class, women and men generally had the same impact (i.e., citations). In certain maledominated fields, such as geology, women even out performed men in terms of impact. There were however, significantly fewer women in the highest productivity class (32 papers or more over a four-year period). As a result, when looking at overall publishing rates, women are producing $67 \%$ of what their male colleagues do. This number is virtually unchanged from that reported for the 1960s (65\%).

If the academic pipeline was really working, the productivity differences between the genders should have declined over the last half-century. The authors propose that women get stuck in a vicious cycle with lower academic positions and fewer leadership roles, which leads to less research money, visibility and impact, as well as diminished productivity. This prevents women from getting into that crucial top productivity category, further reinforcing gender bias in research, and keeping the proverbial glass ceiling in place. The lower status of women has been further confirmed by a recent examination of Nature articles between 2008 and 2016 where only $18 \%$ of the prestigious last author positions (i.e., research leader) were occupied by women ${ }^{4}$.

\section{Discrimination, harassment and unconscious bias}

Women in academia also face barriers related to how we interact with each other. A positive outcome of the \#metoo campaign is that awareness about direct discrimination and sexual harassment has increased, and moved it into an even more socially unacceptable place. Sexual harassment in field-based disciplines is common, with a reported $64 \%$ of women having experienced some form of inappropriate sexual behaviour, and just over $20 \%$ being victims of sexual assault when in the field 5 . In comparison to private and governmental sectors, women in academia reported higher rates of sexual harassment (58\%), which was topped only by women in the military (69\%)-both male-dominated fields ${ }^{6}$. It is perhaps not surprising that research shows that this leads to lower job satisfaction and lower retention of women in science?.

Even for those who actively work against discrimination and harassment, there are still a number of unconscious biases that need tackling. A well-cited example of unconscious bias comes from Corinne Moss-Racusin and co-workers ${ }^{8}$. People were asked to evaluate one of two CVs for a laboratory position with the only difference being the sex of the applicant. In comparison to the female candidate, evaluators, regardless of gender, consistently rated male applicants as more qualified, giving them higher starting salaries and more mentoring (although the female applicant was more "likable"). Examination of reference letters for postdoctoral fellowships showed that females were less likely to receive excellent letters versus good letters than male applicants and that letters were shorter in length, regardless of the gender of the referee $^{9}$. There is also a tendency to use more "grindstone" (e.g., industrious, conscientious, dependable), rather than "stand out" terms (e.g., exceptional, amazing, magnificent) to describe women, which could limit their chances of winning prestigious positions ${ }^{10}$.

One could link this language to cultural stereotypes of women in the western world. In general, women are expected to be nurturing and socially orientated, while men are expected to be achievement orientated and competitive. Studies have shown that men benefit more than women when they show altruistic behaviour in the workplace, since it goes against our unconscious expectations of men. Conversely, a woman who doesn't show altruistic behaviour is more heavily penalized than a man with the same behaviour, regardless of whether the person making the behaviour judgement was male or female ${ }^{11}$. In the same vein, women have been shown to experience a "co-author penalty". Men and women who produce single-author papers are as likely as each other to receive tenure, whereas women who co-author more papers are less likely to be given tenure than men who do the same ${ }^{12}$.

\section{Advantages of gender parity}

We are facing a future shortage of people in the Science, Technology, Engineering and Mathematics (STEM) fields. As such, we cannot afford to exclude people based on gender, ethnicity, sexuality or religion. And we work better together. Diverse teams perform better than those comprised of only women or only men. The collective intelligence of the group exceeds that predicted by the individual IQ of the members. Both the groups' collective intelligence and equality in participation increased with the number of women in the group ${ }^{13,14}$. In contrast to people working in homogenous groups, 

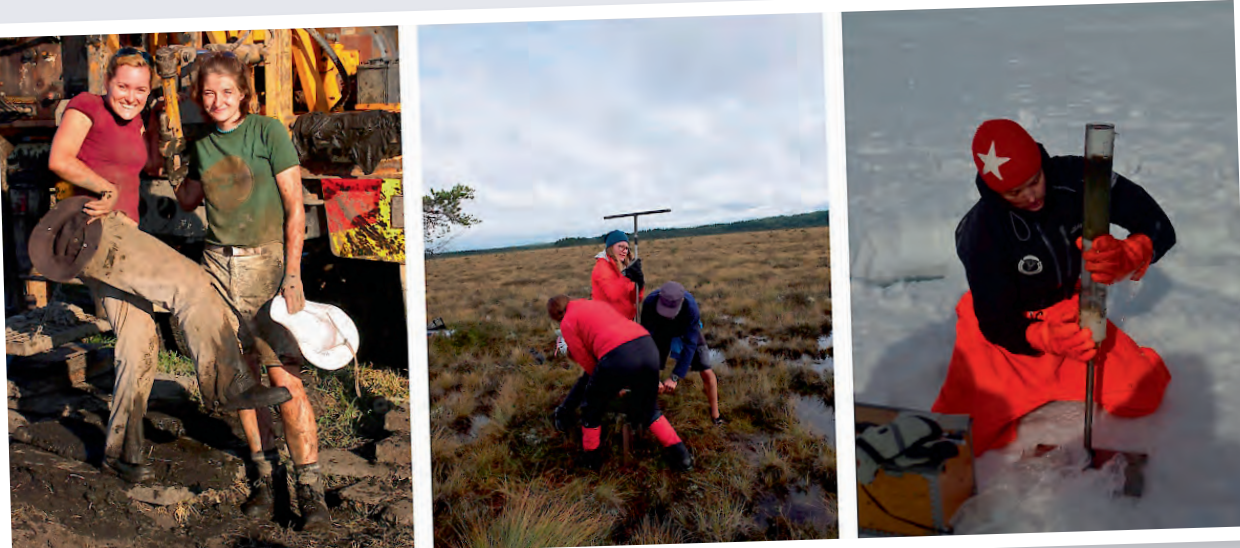
Times have changed since Mary Anning's days and women don't siöström and Mikaela Holm, Stockholm University and Muller, Florida Gulf Coast University and the author), peats (Jenny Sjostrom and Mnown. $\odot$ Malin Kylander

people working in groups

with greater diversity (not just in terms of gender or expertise) tend to be better prepared. They don't necessarily expect to reach consensus as easily since they are not assured that the rest of the group will share the same opinions. Rather, there are more unique perspectives, information and experiences being shared. This leads to greater creativity and problem solving ${ }^{15}$.

\section{Levelling the field}

So, what can we do on a daily basis to reach gender parity? Institutional leadership has been found to be important for improving workplace conditions for women, as it sets the tone for what is acceptable or not, particularly when it comes to sexual harassment. Women who described their departments as having good collaboration, cooperation, respect and collegiality had higher job satisfaction, productivity and felt influence?. Institutions can foster an inclusive environment by making sure everyone receives the same information through formalized channels of departmental communication.

Expectations from the leadership can be made clear by having written codes of conduct, while assessment (e.g. for promotion) and recruitment processes should be transparent and involve gender-balanced panels.

We can all support minorities around us. If you are in a meeting and a female colleague is interrupted, redirect the conversation ("I would really like to finish hearing what Jenny has to say..."). If you catch a colleague condescendingly explaining to a woman something that she clearly knows (so called "mansplaining"), give them a nudge. If you are in a position to organize speakers, committees, teaching staff, etc., strive to have diverse representation of your research community. Mentorship can also improve a person's chance of staying in academics. Mentors can provide mentees with an outside perspective on their research process, introduce them to the unwritten rules of their research community, as well as provide extra encouragement, career advice and contacts. Five years ago, along with my colleague Agatha de Boer, we launched a mentorship programme at the Bolin Centre for Climate Research at Stockholm University, Sweden. This programme was open to everyone, regardless of rank or discipline. By and far the most requests we get are from junior female researchers asking for senior female mentors. As the saying goes, you cannot be what you cannot see.

For women, be seen. If you are given the chance to play a leadership role, take it. At meetings, sit where you can be seen and heard. For example, in Sweden, it is required that at least one member of a PhD examination committee is female. While nobody likes to be the token representative, I think of the women in the auditorium behind me-they see a woman where the decisions are being made.

\section{Removing gender biases}

We can help ourselves be more objective by removing some of the gender cues we unconsciously look for. In the world of music, the introduction of blind auditions for symphony orchestras in the 1970s can explain the $30 \%$ increase in the proportion of women being hired. While it may be hard to apply this model in the merit-based world of research, wherever possible when evaluating applications, project proposals and scientific publications, we should use double-blind reviews. Budden et al. ${ }^{16}$ found that representation of female first authors increased 33\% when double-blind review of manuscripts was used.

Awareness is the key to reducing gender biases, which are held by both sexes and unfair to men and women alike. The best way to achieve this in science is by using science. We have studies and data, just a handful of which are discussed above, that show women are at a disadvantage in the research world. We cannot be complacent and wait passively for the pipeline to do its job. We need to help women get up the academic ladder and lead the way for coming generations. To that end, I am pleased to say that our department installed its first female professor in 2007 with another two following in 2010, allowing all the women who follow to believe that we too can have our portraits placed on the wall.

End Note: This article is slightly modified from the original: Kylander, M. (2019, Jan). Outnumbered and Surrounded: Women Working in Male Dominated Research Fields: Women in Science. Angle Journal. Retrieved from http://anglejournal.com/article/2018-12outnumbered-and-surrounded-womenworking-in-male-dominated-researchfields-women-in-science-000128 (Published under a CC BY-ND license). References are available online.

Dr. Malin Kylander is an Associate Professor at the Department of Geological Sciences and the Bolin Centre for Climate Research at Stockholm University; e-mail: malin.kylander@geo.su.se 